University of Nebraska - Lincoln

DigitalCommons@University of Nebraska - Lincoln

Faculty Publications, Department of Child, Youth, and Family Studies

Child, Youth, and Family Studies, Department of

$9-2011$

\title{
Grandparenting in Chinese Immigrant Families
}

Xiaolin Xie

Northern Illinois University, xialinx@niu.edu

Yan Xia

University of Nebraska-Lincoln, rxia2@unl.edu

Follow this and additional works at: https://digitalcommons.unl.edu/famconfacpub

Xie, Xiaolin and Xia, Yan, "Grandparenting in Chinese Immigrant Families" (2011). Faculty Publications, Department of Child, Youth, and Family Studies. 82.

https://digitalcommons.unl.edu/famconfacpub/82

This Article is brought to you for free and open access by the Child, Youth, and Family Studies, Department of at DigitalCommons@University of Nebraska - Lincoln. It has been accepted for inclusion in Faculty Publications, Department of Child, Youth, and Family Studies by an authorized administrator of DigitalCommons@University of Nebraska - Lincoln. 
Published in Marriage and Family Review 47:6 (2011), pp. 383-396;

doi: 10.1080/01494929.2011.594218

Copyright (C) Taylor and Francis Group, LLC. Used by permission.

Published September 15, 2011

\title{
Grandparenting in Chinese Immigrant Families
}

\author{
Xiaolin $\mathrm{Xie}^{1}$ and Yan Xia ${ }^{2}$ \\ 1. Department of Family, Consumer, and Nutrition Sciences, \\ Northern Illinois University, DeKalb, Illinois, USA \\ 2. Department of Child, Youth, and Family Studies, \\ University of Nebraska-Lincoln, Lincoln, Nebraska, USA \\ Corresponding author - Xiaolin Xie, Department of Family, Consumer, and Nutrition Sciences, \\ Northern Illinois University, 1425 West Lincoln Hwy., DeKalb, IL 6o115-2828, USA; \\ email xiaolinx@niu.edu
}

\begin{abstract}
In light of the life course perspective, this semistructured interview study with 29 grandparents involved in the caregiving of their grandchildren in Chinese immigrant families revealed three major themes: intergenerational connectedness and continuity of cultural practices, role varieties and responsibilities, and adjustment and adaptation. Despite immigration, Chinese grandparents continued the tradition of providing care to grandchildren. Although the grandparent role entailed responsibilities and there were adjustments to make when living in the new place, overall, grandparents considered their caregiving experiences positive. Support to these grandparents, however, was needed at both family and community levels to ensure their stay in the United States and their continuous contribution to their adult children's lives.
\end{abstract}

\section{Introduction}

The research on grandparenting has received ample attention in Western literature. Grandparents' responsibilities run the gamut from socialization of grandchildren (Gibson, 2005; Thiele and Whelan, 2010) to providing financial resources to the younger generation (Silverstein and Giarrusso, 2010). Research on the same topic against the backdrop of Chinese immigrant families, however, is scant. The goal of this study therefore was to examine the role grandpar- 
ents played in Chinese immigrant families, their contribution to their adult children's family system, and the support system at various levels to which they are entitled. To begin to explore these issues, life course perspective and intergenerational solidarity and conflict model were used to guide this study, followed by some related research.

\section{Life Course Perspective}

Life course perspective calls attention to the interconnectedness of family lives across generations. This perspective is conducive to understanding Chinese immigrant families, because Chinese culture is known for its emphasis on family cohesion and harmony. In fact, to achieve this cohesion families tend to take precedence over individuals (Hsu, 1985). To fully comprehend this framework, several concepts related to this perspective are discussed: roles, transitions, turning points, and linked lives.

Roles refer to the position that each person occupies within a social institution, for instance, family, paid work, and school (Hutchinson, 2005). As a result there are culturally and socially prescribed role expectations for each specific role the individual plays, such as parent and grandparent. At the same time each person plays multiple roles within or across various social institutions (Hutchinson, 2005).

Transitions refer to the normative or non-normative life events that bring about changes in one's life. The life course perspective contends that people go through a number of transitions throughout their lifetimes, such as getting married, having a child, and becoming a grandparent. Transitions can induce change and stress in the family system and require internal and/or external resources to go through these stages. For instance, a career-oriented couple having a child necessitates negotiation of work schedules and childcare.

Turning points are special life events that produce lasting and significant changes. Rutter (1996) suggested three types of life events that can become turning points in one's life: (1) life events that close or open opportunities, (2) life events that have a lasting impact on one's surroundings, and (3) life events that change one's self-image, beliefs, and expectations. A major turning point in immigrant families is migration to the United States. This event is multifaceted in that it alters one's social support network, opens an opportunity for developing a new identity in a new environment, and it has a lasting influence on one's family network.

Linked lives refer to the interconnectedness of human relationships in a social setting in which individuals support and control each other's behavior throughout the lifespan (Hutchison, 2005). The family is depicted as the major social support network for the individual. Parents and children are interdependent and mutually influential in their lives throughout the lifespan. 


\section{Grandparenting in the Chinese Cultural Context}

Research finds that taking care of grandchildren is most predictive of grandparent behavior for the Chinese (Strom et al., 1999), compared with Western cultures. This is especially true in rural China where adult children seek employment in cities and leave their young children to the grandparents (Silverstein, Cong, and Li, 2006).

Chinese families are influenced by Confucianism, which dictates the structure and function of intergenerational relationships. Families remain the cornerstone of all types of support. Sun (2002) defined this type of support model as the corporate group/mutual aid model that allowed family members to be interdependent and to offer mutual assistance when in need. One example of this model is when grandparents take care of their grandchildren, at least when the latter are still young.

Chinese immigrant families continue to adopt the corporate group/mutual aid model when they come to the United States by inviting grandparents to care for their grandchildren. In recent decades, when Chinese young adults came to the United States to pursue higher education and, eventually, to start a family, it was common practice to call on their parents to provide child care to youngsters. The free child care was sought by adult children who struggled to balance work and childrearing. As soon as they arrived in the United States, seniors were quick to integrate into the family network and contribute to family care and support. They were more likely to reside with their kin than their White counterparts (Burr and Mutchler, 1993).

In their qualitative study, Treas and Mazumdar (2004) revealed that immigrant elderly were valuable resources to their adult children in America and contributed to the family in various ways. First, they provided physical care to family members, such as taking care of grandchildren. Second, they had domestic duties, such as housekeeping and child care. Third, they took on responsibilities of maintaining culture and preserving family, such as teaching traditions, preparing ethnic foods, and teaching their own languages to younger generations. Seniors with more than one child in the United States rotated residency among adult children's home over a period of years to care for a succession of youngsters (Treas and Mazumdar, 2004).

Taking care of small children is, understandably, a demanding job. Many foreign-born elders take on full-time responsibility as the involved grandparents, a practice that is not so common in Western culture (Cherlin and Furstenberg, 1986). Because of the nature of their work, immigrant grandparents, often socially invisible, contribute heavily to the financial state of their adult children by saving the child care cost and making it possible for both parents to continue working. This represents the beneficial side of the mutual aid model for adult children.

On the other side of the mutual aid model, seniors received satisfaction from their involvement in the lives of their adult children and grandchildren. They 
found their current lives, with challenges, were more interesting and less lonely and isolated. In fact, in some cases the two sets of grandparents competed for the opportunity to nurture and care for their grandchildren (Sheng and Settles, 2006). They ended up rotating their care work for their grandchildren.

\section{Purpose of the Study}

The study of grandparenting among Chinese immigrant families has not received much attention. The purpose of this study is to gather insights from grandparents who provided care to their grandchildren on the roles they played and their motivation to provide care and support and to gain an understanding of grandparenting among Chinese immigrant families through the lens of the life course perspective.

\section{Methods}

\section{Sample}

The 29 grandparents were contacted through friends of the lead researcher and local Chinese church. All participants resided in the suburbs of a large Midwestern city and provided care to one of their grandchildren under 5 years old for at least 6 months in the past year. Their ages ranged from 55 to 77 years. Of the 29 participants, 11 were couples and 7 came to the United States alone. All but one were retired by the time they came to the United States. Information about the 29 grandparents is provided in Table 1. For privacy reason all names listed are pseudonyms.

\section{Procedure}

Because of the "transient and difficult-to-reach" nature of this population group, a quantitative study was not feasible (Treas and Mazumdar, 2004). Instead, a qualitative methodology was used. Qualitative research is an investigation process in which the researcher gradually makes sense of a social phenomenon by constructing, comparing, replicating, categorizing, and classifying the objects of study (Miles and Huberman, 1984). Qualitative research is appropriate for ascertaining meanings within the private domain of family life (Daly, 1992).

As in other studies that gear toward the significance of grandparenting, the commonly used qualitative semistructured interview was implemented for this study. It involved a direct concern with experience as it was "lived" or "felt" or "undergone." This research method aims to understand life experiences as closely as possible to the way participants believe it or live it (Sherman and Webb, 1988). 
Table 1. Information About the 29 Grandparents

\begin{tabular}{|c|c|c|c|c|}
\hline Names ${ }^{\text {a }}$ & $\begin{array}{l}\text { Length } \\
\text { of } \\
\text { stay } \\
\text { (years) }\end{array}$ & $\begin{array}{l}\text { Permanent } \\
\text { resident of } \\
\text { the United } \\
\text { States }\end{array}$ & $\begin{array}{l}\text { Adult child } \\
\text { they live } \\
\text { with in the } \\
\text { United States }\end{array}$ & $\begin{array}{l}\text { Previously } \\
\text { held } \\
\text { profession } \\
\text { in China }\end{array}$ \\
\hline Mr. and Mrs. Li & 7 & Yes & Son & Government officials \\
\hline Mr. and Mrs. Lin & 5 & Yes & Son & Government officials \\
\hline Mr. and Mrs. Wang & 5 & Yes & Daughter & Physicians \\
\hline Mr. and Mrs. Wu & 6 & Yes & Son & College professors \\
\hline Mr. and Mrs. Xiao & 1 & No & Daughter & Factory worker and nurse \\
\hline Mr. and Mrs. Xu & 1 & No & Daughter & Physicians \\
\hline Mr. and Mrs. Yang & 3 & Yes & Daughter & Physicians \\
\hline Mr. and Mrs. Zhang & 4 & Yes & Son & Physicians \\
\hline Mr. and Mrs. Zhao & 1 & No & Daughter & Physicians \\
\hline Mr. and Mrs. Zhi & 5 & Yes & Son & Psychologists \\
\hline Mr. and Mrs. Zhu & 2 & No & Daughter & Physicians \\
\hline Mrs. Chen & 3 & Yes & Son & College professor \\
\hline Mrs. Gu & 8 & Yes & Daughter & Factory worker \\
\hline Mrs. Liu & 4 & Yes & Daughter & Physician \\
\hline Mrs. Mei & 1 & No & Daughter & Factory worker \\
\hline Mrs. Yin & 1 & No & Daughter & High school teacher \\
\hline Mrs. Yuan & 7 & Yes & Son & Chinese medicine doctor \\
\hline Mrs. Zhen & 3 & Yes & Son & Chinese medicine doctor \\
\hline
\end{tabular}

a. All names are pseudonyms.

Besides conducting personal interviews, the lead author also played the participant-as-observer role. Because she is a Chinese immigrant, her parents live close by, and she drives seniors to English classes on the weekends, she was able to play this dual role. Through all these events she also was able to form close relationships with grandparents and conduct casual conversations with them about their grandparenting roles and responsibilities. She participated in many of their activities, such as English-learning classes, dance classes, a health fair at the Asian Community, and Chinese New Year and mid-autumn festival parties. During these events she informed the centers and seniors about her researcher purposes. By adopting this participant-as-observer role she was able to collect additional information related to this topic.

Each interview with the 29 grandparents lasted between 30 and 90 minutes. All interviews were taped when permitted and transcribed verbatim. They were conducted at the interviewees' homes, at the Asian Community Center, or at the local Chinese church. They were interviewed in their main dialect, in this case Mandarin or Cantonese. The first author was fluent in both dialects and collected the data herself.

General questions to grandparents included the following: What was grandparenting like in the United States? How would you describe your role as a 
grandparent? By encouraging grandparents to share their stories, the research was bringing to light many "invisible" meanings and perspectives surrounding the issue of grandparents as caregivers.

A life history profile was compiled for each participant that included demographic information, immigrant history and travel routines, and daily activities. Demographic information included age, marital status, number of adult children in the United States and in China, work status before coming to the United States, education background, religion, and health status. The first author who collected the data also kept a journal during the entire data collection process. Analysis was guided by grounded theory (Strauss and Corbin, 1998). The authors read and reread all interviews, and similar experiences were grouped together to explicate recurrent patterns and themes. After multiple readings and constant comparisons among cases, three major categories and themes were identified: cultural practices, role varieties and responsibilities, and adjustment and adaptation.

\section{Results}

Three predominant themes related to grandparents as caregivers emerged from the interview: intergenerational connectedness and continuity of cultural practices, role variety and responsibilities, adjustment and adaptation. These themes are discussed below.

\section{Intergenerational Connectedness and Continuity of Cultural Practices}

Chinese families have long been described as a corporate kin group that cared for the welfare of all family members and were bound by common goals and interests (Tu, Freedman, and Wolf, 1993). Family relationships are intergenerational. The Chinese grandparents in the current study saw it as their normative responsibility to offer support and assistance when their adult children became parents for the first time. One retired grandma shared the following:

At the time when my son had his first son, I was teaching. What is more important? My work or my grandchild? Of course, my grandchild.

Subsequently, she applied for early retirement and came to her son's rescue.

Many adult children in this study were in a dual-career marriage, so juggling work and family could be taxing to the young couples. To protect their job security and financial stability both husband and wife continued their work after the birth of their child. Child care can be expensive, and many parents find it hard to leave their newborn babies with strangers. Even though they are now living 
in the United States, they rely on their cultural practice-bringing grandparents from thousands of miles away to assist with their major life event: parenthood. One grandfather shared the following:

I was teaching graduate students at the time. My wife told me to quit my work on campus and help my son. So, here I am.

It was interesting that many of these grandparents defied the traditional roles of grandparents. Before retirement or coming to the United States they held professional jobs, such as physicians, college professors, and government officials. Yet, when needed by their adult children, they prized their family roles over their professional roles. One grandma stated that her greatest joy was to see her children do well in their lives.

Doing well implies success in both career and family lives. Some grandparents make sure their children achieve this success even at the expense of their own sacrifices. One grandfather was still teaching at a university at the time his first grandchild arrived. He shared the following:

I loved my work, and I was making good money, but my wife asked me quit my job and to come to the US to help our son. I did right away.

Others managed to balance different roles in two countries. One first-time grandma who had been separated from her daughter for several years was excited to come to help her daughter with child care. However, at the time when she left for the United States her son's wife was about to give birth to his first child and her husband was just diagnosed with diabetes. She was caught between three places but decided to help her daughter first since "she has no other relatives around her." She arranged for her in-laws to help her son with his new infant. As soon as her 1-year visa was up, she flew back home to be with her husband and to celebrate her other grandchild's first birthday.

These grandparents also had other family roles to fulfill, such as caring for their aging parents in China. One grandma in her late 6os shared her balancing act:

My own mom was in her late 8o s when I first came. She was living with me, but my son was in desperate need of my help, so I asked my sister to take care of my mom. I gave my sister all my retirement income and I flew back to visit my mom every year.

Grandparenting implied sacrifice and commitment. They gave up their career, time, social network, and familiar routine to provide assistance to their children in the United States. This activity enriched and brought meaning to their retirement life. Some shared the joy of being close to their grandchildren 
and watching them grow. They shared their pride in their adult children and grandchildren. One grandpa shared the following:

I love children. They make me forget my own age and aging. I am always happy around my grandchildren. Now that I am retired, I don't feel bored or lonely with them around.

\section{Role Variety and Responsibilities}

These grandparents' roles ran the gamut of cooking, caregiving, language teachers, and math tutors. In several cases grandparents also served as an anchor in their adult children and grandchildren's lives in crisis situations, such as illness and divorce. At times, their role responsibilities entail hard work and long hours. One grandma who lived with her daughter for the past 10 years and has been taking care of her two granddaughters under 8 years old stated the following:

It gets pretty busy during the day. I cook and clean, and help the two granddaughters with their piano practice. One of them has diabetes, so twice a day I give her shots. My daughter has a very busy work schedule. She leaves early in the morning and comes home after 7 or 8. She does not have much energy left to take care of the two girls after work.

Many grandparents reported being surprised at the adult children's busy work schedule. That gave them the incentive to help out anyway they could. One grandma with two grandchildren under 4 years old shared the following:

I hardly see my daughter during the daytime. She leaves home at 6 am to catch the bus to the train stop and then to downtown Chicago. She does not come home until 8 or $9 \mathrm{pm}$. If she had been in China now, she would not have to work this hard. So, my husband and I would do as much as we can during the day.

Another grandma shared as follows: "I think my children work much harder here than in China." As a result these grandparents strive to relieve their children's household chores, such as cooking, cleaning, and child care.

The role responsibilities change when the grandchildren are growing up. When the grandchildren enter preschool or kindergarten, it is only natural for them to take up reading, math, and Chinese language learning. The responsibilities of teaching grandchildren new skills fall on grandparents' shoulders.

At times, some major life events or turning points in adult children's lives called for the help of grandparents. One grandma came when her son's marriage was falling apart. With her son's busy travel schedule and her daughter-in-law 
moving out, she became the primary caregiver to her two grandchildren under age 10. Besides supervising their regular school studies, she also supervised their weekend Chinese studies on top of cooking and cleaning for them.

Some grandparents in this study had more than one child living in the United States. Their service and assistance were needed in their adult children's households. To solve this issue, grandparents rotated helping out children living in different parts of the United States. One grandma came to Illinois to help her son after helping her daughter in New York. Another came to the United States after helping her daughter in New Zealand. Sometimes, the senior couple had to separate themselves to help their adult children. One grandma lived with her daughter who had two school-aged grandchildren in Illinois, whereas her husband lived in Maryland to help the other daughter with a toddler. This arrangement lasted for over a year. Some seniors spent years providing care for their grandchildren. One grandma who came with her husband to help their son stayed 15 years because their son subsequently had four children. During these periods of child care many of these grandparents traveled back and forth between China and the United States to fulfill the various roles they played in both countries.

There were a few grandfathers in this study, all of whom came to the United States with their spouses. Their role performance varied to some degree from that of their spouses. Grandfathers tend to fulfill more activity-oriented or instrumental responsibilities. One grandfather taught his grandson kong fu, which his 7-year-old grandson enjoyed. Another grandfather enjoyed cooking, fixing things around the house, and doing yard work.

\section{Adjustment and Adaptation}

As mentioned previously, many grandparents in this study held professional careers in China. They dreamed about coming to the United States to visit their children after years of separation; however, migration entailed changes in support systems and stress. Despite the joy of reunion with their families and the excitement of sharing their children's success in the United States, the grandparents reported the adjustments and challenges of living in a foreign land, such as lacking mobility around town, not being able to communicate in English, and not having the organized community activities for seniors as they enjoyed in China. One grandpa shared his comments when he first came to the United States:

Sometimes, it gets very quiet in the house. I can't go around the city as transportation is not as convenient as in China. I can't understand the local TV or read their newspaper. It is so quiet here. 
Adjustment also included changing their parenting practices to conform to those of their adult children. As Chinese culture emphasizes harmony and unity, it is not conventional for grandparents to express their concerns and issues publicly. Some grandparents hinted they were not in charge and this was really their adult children's household; therefore, they reminded themselves to demure to their children's rules, for example, cosleeping. Some grandparents found it puzzling to see their adult children put an infant to bed in a different room at night. They believed it was important and necessary for parents to cosleep with their baby so they would not be "afraid or scared" at night. They concluded their adult children took up a Western practice that was not healthy or beneficial to their grandchildren. However, after their suggestion of cosleeping was rejected, they decided they were helpers at their adult children's family. One grandma who was dealing with this issue shared the following: "She [her daughter] is the mother. Of course, she decides."

Other adjustments were related to in-law relationships or intergenerational relationships. Some grandparents reported not receiving enough respect from daughters-in-law or their adult children who were becoming "too Americanized." Their children were not the same as the ones they knew in China. One grandma commented, "I can't get along with my daughter-in-law. She seems to check on me all the time and correct everything I do."

Grandparenting in the United States can be stressful because the community support network is not available. Some grandparents stated that in some ways it was harder to provide child care for their grandchildren in the United States than in China; for example, to hire a nanny to help with housework in China represented a small expense. Here in the United States where labor is more expensive, grandparents had to do it all. This is especially hard for grandparents who played the role of "involved" grandparents or even "surrogate parents." In one situation the adult children were assigned to work in a different city, and they only came home on the weekends. As a result grandpa and grandma cared for their two grandsons during weekdays. They got some time off only during the weekends when both parents came home.

Grandparents were not shy about sharing how their adult children appreciated their assistance and contribution and how they tried to lessen their parents' isolation and loneliness by installing ethnic Chinese TV, teaching them how to assess the Internet, and inviting them to vacation. Interestingly, these grandparents searched outside the immediate family for support and connection. With the increasing number of immigrant seniors in the suburb of Chicago, community centers started to cater to needs of such seniors by establishing various classes, such as a conversational English class, citizenship exam preparation class, and tai chi class, and providing them with helpful information on health-related topics. Local ethnic churches also provided another channel for grandparents to meet their peers and make new friends. 
After a period of adjustment to the new lifestyle in the United States, many grandparents seemed to adapt and adjust. As mentioned previously, many of them were professionals, so in their peer group gatherings they offered workshops related to their professions. Retired physicians would hold workshops on various health-related issues, and psychologists would offer counseling to seniors who were still struggling in their adjustment. Many grandparents reported looking forward to socializing with their peers on the weekends, taking dancing, singing, English, and tai chi classes. They were happy to have some time to relax and recuperate from their daily grind of caregiving activities.

\section{Discussion}

This qualitative study of in-depth interviews with 29 grandparents revealed three major themes: intergenerational connectedness and continuity of cultural practices, role variety and responsibilities, and adjustment and adaptation. In light of the life course perspective, Chinese parents and their adult children continue to demonstrate that their lives in many ways are linked despite migration. Family bonds defy physical separation and migration. Major life events or turning points are accompanied, witnessed, and supported by families.

The seniors in this study stepped into their role of grandparents with joy, excitement, and anticipation. Immigration status of their adult children, however, challenges their fulfillment of their responsibilities. Many of them sacrificed and contributed heavily to the interest of their adult children and grandchildren by putting aside their professional work in China and stepping into an unfamiliar place. Consistent with research on similar topics (Treas, 2008), these seniors came to the United States to provide much needed assistance to their adult children and to be close to their families. Because some of them had all their adult children in the United States, staying in China by themselves did not seem to make much sense. Therefore, they agreed to be sponsored by their adult children to become legal immigrants.

Because migration is a major turning point in both adult children and their parents' lives, this to some degree accentuates their linked lives. Not only were seniors' lives linked to their adult children's families but to the outside world and larger community as well. Any connection to the community helped alleviate the stress and loneliness of living in a place where they could not understand the language and had limited mobility around town. Weekend activities targeted for this group of seniors, such as English classes and health education workshops, were events to which they looked forward. Through these events they were able to socialize with their own age group and take a break from their child care choirs.

They adapted and adjusted to the new environment by reaching out to lo- 
cate support groups or to even form their own support groups in the community. It is interesting to see how this group of seniors, mostly college-educated, differed from the early Chinese immigrant seniors described in the research as frail, poor, and depressed (Ada, 2006).

After many years of grandparenting in the United States, some seniors became American residents; however, this did not mean they severed all home culture contacts. Many Chinese adopted transnational activities, such as rotating living in the United States and in China. With family members in both worlds, many traveled to and from both countries to fulfill various role responsibilities they still carried. Visiting their home country gave them "a chance to immerse oneself in a familiar culture and to revisit one's own personal history" (Treas, 2008, p. 472). Their lives, therefore, cover multiple contexts and regions.

This qualitative study found that grandparents continued to adapt and adjust in new contexts. Many faced challenges at the initial stages, such as lack of language skills and mobility around town, in-laws issues, and isolation and loneliness. Gradually, they searched for, found, or established support in the community, which gave meaning to their stay in the United States.

\section{Implications}

The increasing number of Chinese immigrant seniors necessitates establishing support systems and networks at the community level. Local social service agencies need to be aware of Chinese immigrants' cultural practices of intergenerational support and assistance and provide channels for such seniors to socialize with their own peers and recuperate from daily grandchild care. Currently, some ethnic community centers provide English-learning classes and tai chi classes and celebrate ethnic holidays. Many seniors gravitate to these cultural activities to bridge the gap between their host and home countries.

\section{Limitations}

There are two major limitations to this study. First, most grandparents were from a relatively homogeneous group: relatively healthy, college-educated, and professional before retirement. Second, this qualitative study would not allow any generalization to the larger sample. Interviews with other seniors with different social economic status are encouraged in the future. 


\section{References}

Ada, M., and Kang, S. Y. (2006). Acculturation stress and depression among Asian immigrant elders. Social Work, 51, 243-255.

Burr, J. A., and Mutchler, J. E. (1993). Ethnic living arrangements: Cultural convergence or cultural manifestation? Social Forces, 72 (1), 169-179.

Cherlin, A. J., and Furstenberg, F. F. (1986). The new American grandparent. New York, NY: Basic Books.

Daly, K. (1992). The fit between qualitative research and characteristics of families. In J. Gilgun and K. Daly (eds.), Qualitative methods in family research. Newbury Park, CA: Sage.

Gibson, P. A. (2005). Intergenerational parenting from the perspective of African American grandmothers. Family Relations, 54, 280-297.,

Hsu, J. (1985). The Chinese family: Relations, problems and therapy. In W. Tseng and D. Y. Wu (eds.), Chinese culture and mental health (pp. 95-112). Orlando, FL: Academic Press.

Hu, R., and Ye, N. (1991). The nine-city survey on aging in 1988. Tianjin, China: Tianjin Educational Press.

Hutchinson, E. (2005). The life course perspective: A promising approach for bridging the micro and macro worlds for social workers. Families in Society, 86 (1), $143^{-152 .}$

Kornhaber, A. (1996). Contemporary grandparenting. Thousand Oaks, CA: Sage.

Miles, M. B., and Huberman, A. M. (1984). Qualitative data analysis: A sourcebook of new methods. Thousand Oaks, CA: Sage.

Rutter, M. (1996). Transitions and turning points in developmental psychopathology: As applied to the age span between childhood and mid-adulthood. International Journal of Behavioral Development, 19, 603-636.

Sheng, X., and Settles, B. H. (2006). Intergenerational relationships and elderly care in China: A global perspective. Current Sociology, 54, 293-313.

Sherman, R., and Webb, R. (1988). Qualitative research in education: Focus and methods. London, UK: Falmer Press.

Silverstein, M., Cong, Z., and Li, S. (2006). Intergenerational transfers and living arrangements of older people in rural China: Consequences for psychological well-being. Journal of Gerontology: Social Sciences, 61, S256-S266.

Silverstein, M., and Giarrusso, R. (2010). Aging and family life: A decade in review. Journal of Marriage and the Family, 72, 1039-1058.

Strauss, A., and Corbin, J. (1998). Basics of qualitative research: Techniques and procedures for developing grounded theory. Newbury Park, CA: Sage. 
Strom, R. D., Strom, S. K., Wang, C., Shen, Y., Griswold, D., Chan, H., and Yang, C. Y. (1999). Grandparents in the United States and the Republic of China: A comparison of generations and cultures. International Journal of Aging and Human Development, 49 (4), 279-317.

Sun, R. J. (2002). Old age support in contemporary urban China from both parents' and children's perspectives. Research on Aging, 24 (3), 337-359.

Thiele, D. M., and Whelan, T. A. (2010). The nature and dimensions of grandparent role. Marriage and Family Review, 40, 93-109.

Treas, J. (2008). Transnational older adults and their families. Family Relations, 57, 468-478.,

Treas, J., and Mazumdar, S. (2004). Caregiving and kinkeeping: Contribution of older people to America's immigrant families. Journal of Comparative Family Studies, 35, 105-122.

Tu, E. J., Freeman, V. A., and Wolf, D. A. (1993). Kinship and family support in Taiwan. Research on Aging, 15, 465-486. 